\title{
EVALUATION OF THE VARIABLES THAT INFLUENCE MERCURY CAPTURE IN SOLID SORBENTS
}

\author{
M.A. LÓPEZ-ANTÓN, P. ABAD-VALLE, M. DÍAZ-SOMOANO \\ and M.R. MARTÍNEZ-TARAZONA \\ Instituto Nacional del Carbón (CSIC), \\ Francisco Pintado Fé $n^{\circ} 26,33011$, Oviedo, Spain \\ e-mail: rmtarazona@incar.csic.es
}

\section{EXTENDED ABSTRACT}

Fly ashes are by-products generated during coal combustion in power plants. These byproducts are able to capture volatile species, such as mercury that are evaporated from coal in different proportions. The precise mechanism by which a trace element is retained in the fly ashes is not fully understood. The quantity of mercury retained may vary from fly ash to fly ash and depends on the process conditions. It has been observed that, although some fly ash inorganic components exhibit a low capacity for mercury retention, the unburned material in the fly ash may benefit its adsorption. There are a number of variables that may influence mercury retention by fly ash components and the exact nature of $\mathrm{Hg}$-fly ash interactions needs to be investigated more thoroughly.

The aim of the present work was to evaluate the variables that have an effect on the retention of $\mathrm{Hg}^{0}$ and $\mathrm{HgCl}_{2}$ in fly ashes originated by burning coals of different rank and nature. The mercury retention capacity of these fly ashes was compared with retention in commercial activated carbons in coal combustion and inert atmospheres. The study was carried out in a laboratory scale reactor using the sorbent as a fixed bed. The amount of mercury retained was determined by analyzing the sorbents post-retention by means of cold vapor atomic absorption (CV-AA).

The results obtained indicate that the quantity of mercury captured depends on the characteristics of the fly ashes and on the mode of occurrence of mercury in gas phase. The retention of mercury in the fly ashes studied is greatly influenced by the gas composition. It was inferred that, unlike the activated carbons, the fly ashes show different retention capacities and efficiencies for mercury in combustion and inert atmospheres. Moreover, mercury retention may be modified by variations in the unburned coal particle content

Keywords: mercury, fly ashes, activated carbons

\section{INTRODUCTION}

Although some of the ashes produced during coal combustion are ejected from the bottom of the boiler, the main proportion is carried out by the combustion gases and is afterwards captured in the particle control devices. These fly ashes constitute most of the waste generated in coal-fired plants. Millions of tons of fly ashes of different characteristics are produced from coal-fired utilities. During 2004, approximately $60 \times 10^{6} \mathrm{t}$ of coal combustion products were generated in Europe. Of these products, a high percentage, $68.2 \%$, were fly ashes [1]. Fly ashes are made up of fine particles consisting of aluminosilicate, glass, quartz, mullite, hematite, ferrite or rutile in various stages of transformation, depending on their origin [2]. They may also contain a variable but small proportion of organic matter (unburned) with a relatively high surface area compared to that of the inorganic fraction. 
Some of the components of the mineral matter found in coal, including trace elements of environmental concern, are volatilized during coal combustion. As a consequence, energy generation from coal is one of the anthropogenic sources of elements such as $\mathrm{Hg}$, $\mathrm{Se}, \mathrm{As}, \mathrm{Cl}$ or $\mathrm{F}$, that are emitted not only in gas phase but also in the particulate matter. The control of the emissions of all these elements is necessary and regulations for mercury emission from coal combustion are now a matter of great concern in USA [3] and Europe [4].

Studies have shown that fly ashes are able to capture some volatile species generated from coal combustion [5-8]. The quantity of elements retained or captured in fly ashes depends on the characteristics of the ashes and process conditions, including the gas cleaning facilities in the power station. The precise mechanism by which a trace element is retained in fly ashes is not fully understood. This matrix is susceptible not only to trace element condensation on the finest particles [8] but also to gas-solid surface reactions in a medium containing metal species in gas phase. Some examples are the chemically controlled surface deposition of lead on particles of fly ashes containing sulfur [9] and reactions of arsenic on the surface of particles containing calcium [10]. In the case of $\mathrm{Hg}$, the proportions of $\mathrm{Hg}$ retained vary depending on the type of fly ash [11]. Recent research has shown that certain fly ash materials have an affinity for mercury and that the unburned material present in fly ash shows considerable retention capacity [12-13]. However, there are a number of variables that may influence mercury capture by fly ashes [11,14], and the exact nature of Hg-fly ash interactions and the influence of the process conditions need to be investigated more thoroughly.

The aim of the present work was to evaluate the variables that have an effect on the retention of mercury in fly ashes taken from power stations which burned coals of different rank and nature. The mercury retention capacity of these fly ashes was compared with retention in commercial activated carbons. The three main variables studied were: $i$ ) the nature and characteristics of the sorbents (raw fly ashes with a small amount of unburned particle content, fly ashes enriched in unburned particles, and activated carbons) ii) the gas atmosphere (nitrogen and a typical coal combustion atmosphere) and iii) the species of mercury in gas phase $\left(\mathrm{Hg}^{0}\right.$ and $\left.\mathrm{HgCl}_{2}\right)$.

\section{EXPERIMENTAL SECTION}

Four fly ash samples (CTA, CTSR, CTES and CTP) and two activated carbons (RBHG3 and RB3) were used as mercury sorbents. CTA, CTSR and CTES were obtained from a pulverized coal power plant (PCC) in which mixtures of high rank coals, bituminous coals and sub bituminous coals were burned, respectively. The fourth fly ash (CTP) was taken from a fluidized bed combustion plant (FBC) that burns mixtures of coal and coal wastes with a high mineral matter content, using limestone in the bed. RBHG3 and RB3 are two commercial activated carbons. Norit RBHG3 was prepared by impregnating Norit RB3 with sulfur compounds. The fly ashes were used in their original sizes $(12-57 \mu \mathrm{m})$ and the activated carbons were ground to a particle size of $0.2-0.5 \mathrm{~mm}$. Fractions of fly ashes enriched in unburned carbon particles were separated on the basis of a previous size fractionation study [15]. Therefore, besides the original fly ashes, three more samples were tested; CTA $>150 \mu \mathrm{m}, \mathrm{CTSR}>80 \mu \mathrm{m}$ and CTES $>200 \mu \mathrm{m}$. In the case of CTP the unburned particles were homogeneously distributed between the different sizes and for this reason only the raw CTP sample was used in this study. All these materials were characterized before being used as sorbents. The elemental composition was determined by atomic absorption spectrometry (AAS), BET surface area by volumetric adsorption of nitrogen at $77 \mathrm{~K}$, and the LOI by combustion at $815^{\circ} \mathrm{C}$.

The experimental equipment used for the retention experiments has already been described in previous works $[11,14]$. It is a laboratory scale device that consists of a glass reactor fitted with an internal and external tube and heated by two different furnaces. $\mathrm{Hg}^{0}(\mathrm{~g})$ and $\mathrm{HgCl}_{2}(\mathrm{~g})$ in the gas atmosphere were obtained by evaporating $\mathrm{Hg}^{0}$ and $\mathrm{HgCl}_{2}$ respectively. The mercury concentrations in gas phase for $\mathrm{Hg}^{0}$ were $0.4 \mu \mathrm{g} \mathrm{ml}^{-1}$ in the 
combustion atmosphere and $0.1 \mathrm{\mu g} \mathrm{ml}^{-1}$ in the inert atmosphere. For $\mathrm{HgCl}_{2}$ it was $0.4 \mu \mathrm{g}$ $\mathrm{ml}^{-1}$ in both atmospheres. A synthetic gas mixture, typical of coal combustion processes, was passed through the reactor. The combustion atmosphere contained $15 \% \mathrm{CO}_{2}, 9.2 \%$ $\mathrm{O}_{2}, 0.2 \% \mathrm{SO}_{2}, 6.6 \% \mathrm{H}_{2} \mathrm{O}$ and was balanced with $\mathrm{N}_{2}$. This mixture carried the element compound in vapour phase through the sorbent bed at a flow rate of $0.5 \mathrm{~L} \mathrm{~min}^{-1}$. The temperature of the sorbent was $120^{\circ} \mathrm{C}$. The element that could not be retained in the sorbent bed was captured in impingers containing $4 \% \mathrm{KMnO}_{4}+10 \% \mathrm{H}_{2} \mathrm{SO}_{4}$ and $\mathrm{HNO}_{3}$ $0.5 \mathrm{~N}$. The amount of mercury retained was determined by analyzing the sorbents postretention by means of cold vapour atomic absorption (CV-AA) after mercury extraction using $60 \%(\mathrm{v} / \mathrm{v}) \mathrm{HNO}_{3}$. Sorption capacity (milligrams of element per $\mathrm{g}$ of sorbent) and efficiency (percentage of element retained) were then evaluated. Maximum retention capacity (MRC) was determined in a series of experiments in which the quantity of the element was gradually increased until the sorbent was saturated.

\section{RESULTS}

The efficiency (\%E) and retention capacity (MRC) values for the fly ashes, fly ash fractions and activated carbons, obtained in different conditions are presented in Table 1. Efficiency was calculated as the average of several determinations and the confidence limit of the results is given as the standard deviation. From these results it can be inferred that the retention of mercury varies greatly in the different fly ashes for the different mercury species and is highly influenced by the gas composition. In contrast, in the activated carbons gas composition does not modify the capture of the species and retention in the combustion and inert atmospheres is the same for both activated carbons. The CTP fly ash behaved in a similar way and retention was not greatly influenced by the gas composition.

\subsection{Influence of the composition and characteristics of the sorbents}

The characteristics of the fly ashes and activated carbons are given in Tables 2-3. The unburned carbon particle content in the fly ashes was determined as LOI (loss on ignition) and is presented in Table 2. The activated carbons have a small mineral content expressed as \% ash (percentage of ashes).

Table 1: Mercury capture in fly ash and activated carbon samples from $\mathrm{Hg}^{0}$ and $\mathrm{HgCl}_{2}$

\begin{tabular}{|c|c|c|c|c|c|c|c|c|}
\hline \multirow[b]{3}{*}{ Sorbent } & \multicolumn{4}{|c|}{$\mathrm{Hg}^{0}$} & \multicolumn{4}{|c|}{$\mathrm{HgCl}_{2}$} \\
\hline & \multicolumn{2}{|c|}{ combustion } & \multicolumn{2}{|c|}{$\mathrm{N}_{2}$} & \multicolumn{2}{|c|}{ combustion } & \multicolumn{2}{|c|}{$\mathbf{N}_{2}$} \\
\hline & $\begin{array}{l}\text { MRC } \\
\text { mg g }^{-1}\end{array}$ & $\% \mathrm{E}$ & $\begin{array}{l}\text { MRC } \\
\mathrm{mg} \mathrm{g}^{-1}\end{array}$ & $\% \mathrm{E}$ & $\begin{array}{c}\text { MRC } \\
\mathrm{mg} \mathrm{g}^{-1}\end{array}$ & $\% \mathrm{E}$ & $\begin{array}{l}\text { MRC } \\
\mathrm{mg} \mathrm{g}^{-1}\end{array}$ & $\% \mathrm{E}$ \\
\hline CTA & 12 & $11 \pm 2$ & 0.3 & $2.7 \pm 1$ & 2.5 & $14 \pm 1$ & 2.5 & $16 \pm 4$ \\
\hline CTA $>150$ & 13 & $15 \pm 2$ & 0.3 & $2.6 \pm 1$ & 2.2 & $17 \pm 3$ & 2.5 & $14 \pm 2$ \\
\hline $\begin{array}{l}\text { CTSR } \\
\text { CTSR }>80\end{array}$ & $\begin{array}{l}25 \\
27\end{array}$ & $\begin{array}{c}8.1 \pm 3 \\
10 \pm 2\end{array}$ & $\begin{array}{l}3.7 \\
3.8\end{array}$ & $\begin{array}{l}16 \pm 2 \\
15 \pm 1\end{array}$ & $\begin{array}{l}12 \\
16\end{array}$ & $\begin{array}{l}21 \pm 1 \\
16 \pm 8\end{array}$ & $\begin{array}{l}3.6 \\
4.3\end{array}$ & $\begin{array}{l}14 \pm 1 \\
11 \pm 2\end{array}$ \\
\hline $\begin{array}{l}\text { CTES } \\
\text { CTES > } 200\end{array}$ & $\begin{array}{l}1.5 \\
9.3\end{array}$ & $\begin{array}{l}1.5 \pm 0.3 \\
2.5 \pm 0.2\end{array}$ & $\begin{array}{l}0.1 \\
0.2\end{array}$ & $\begin{array}{l}0.1 \pm 0 \\
0.2 \pm 0\end{array}$ & $\begin{array}{l}3.2 \\
7.0\end{array}$ & $\begin{array}{l}2.1 \pm 1 \\
5.6 \pm 1\end{array}$ & $\begin{array}{l}1.7 \\
6.5\end{array}$ & $\begin{array}{l}2.3 \pm 1 \\
5.8 \pm 1\end{array}$ \\
\hline CTP & 0.7 & $3.2 \pm 1$ & 0.6 & $2.2 \pm 1$ & 5.0 & $19 \pm 1$ & 5.6 & $23 \pm 2$ \\
\hline RBHG3 & * & $55 \pm 6$ & * & $46 \pm 3$ & 11 & $30 \pm 4$ & 11 & $32 \pm 5$ \\
\hline RB3 & 7.5 & $21 \pm 8$ & 7.5 & $12 \pm 4$ & 10 & $24 \pm 6$ & 10 & $35 \pm 5$ \\
\hline
\end{tabular}

* $150 \mathrm{mg} \mathrm{g}^{-1}$ value supplied by NORIT 
Activated carbons contain more than $90 \%$ wt of carbon material and fly ashes enriched in unburned content have LOI values between 18 and $54 \%$ wt. The raw fly ashes have typical LOI values ranging from 2 to $7.2 \%$ wt. A general comparison of all the samples taken together does not show any clear relation between the quantities of carbonaceous material (Table 2) and mercury retention (Table 1). However, a close examination of the retention by each fly ash and its corresponding fraction shows that retention by the fraction concentrated in carbon is greater in most cases. This was the tendency for both mercury species studied.

Table2: Ash content, LOI, BET surface area and sulphur content in different sorbents

\begin{tabular}{lccc}
\hline Sample & $\begin{array}{c}\text { Ash content } \\
(\%)\end{array}$ & $\begin{array}{c}\text { LOI } \\
(\%)\end{array}$ & $\begin{array}{c}\text { Surface Area } \\
\left(\mathbf{m}^{\mathbf{2}} \mathbf{g}^{-1}\right)\end{array}$ \\
\hline CTA & --- & 5.7 & 1.6 \\
CTA $>150$ & --- & 22 & 4.2 \\
CTSR & --- & 7.2 & 9.4 \\
CTSR>80 & --- & 54 & 17.6 \\
CTES & --- & 2.0 & 1.9 \\
CTES $>200$ & --- & 18 & 13.4 \\
\hline CTP & --- & 3.8 & 6.7 \\
\hline RBHG3 & 5.5 & --- & 868 \\
RB3 & 6.0 & -- & 1183 \\
\hline
\end{tabular}

As regards surface area, fly ashes are non-porous solids, as demonstrated by the $\mathrm{N}_{2}$ adsorption isotherms (type II) and the highest values for surface area were found in CTES $>200$ and CTSR>80 $\left(13.4 \mathrm{~m}^{2} \mathrm{~g}^{-1} ; 17.6 \mathrm{~m}^{2} \mathrm{~g}^{-1}\right)$ as a consequence of an increase in the unburned carbon content. These values are not significant compared to the activated carbons (RBHG3: $868 \mathrm{~m}^{2} \mathrm{~g}^{-1}$; RB3:1183 $\mathrm{m}^{2} \mathrm{~g}^{-1}$ ). The larger surface area does not imply a better mercury capture. As might be expected, RBHG3, which is a commercial activated carbon impregnated with sulfur was the best adsorbent because the mechanisms responsible for mercury capture is chemical adsorption. (Table 1). In the case of RB3 in the combustion atmosphere and with $\mathrm{Hg}^{0}$ as the source of mercury in the gas phase, the MRC was similar or even lower than in the CTA, CTSR and CTES fly ashes, although efficiency was higher Table 1. This may indicate that surface area is not the main factor that affects retention, even though it may control the kinetics of the process.

Table 3: Elemental composition of the inorganic components of the fly ashes and activated carbons (\%wt)

\begin{tabular}{lccccccc|cc}
\hline & CTA & $\begin{array}{c}\text { CTA } \\
>150\end{array}$ & CTSR & $\begin{array}{c}\text { CTSR } \\
\mathbf{8 0}\end{array}$ & CTES & $\begin{array}{c}\text { CTES } \\
>\mathbf{2 0 0}\end{array}$ & CTP & RBHG3 & RB3 \\
\hline $\mathrm{SiO}_{2}$ & 53.3 & 43.2 & 55.3 & 24.2 & 58.5 & 41.0 & 52.1 & 1.86 & 2.58 \\
$\mathrm{Al}_{2} \mathrm{O}_{3}$ & 25.6 & 20.4 & 22.7 & 14.4 & 23.7 & 25.7 & 21.9 & 0.30 & 0.32 \\
$\mathrm{Fe}_{2} \mathrm{O}_{3}$ & 5.87 & 5.14 & 4.84 & 3.49 & 10.5 & 8.38 & 5.97 & 0.27 & 0.29 \\
$\mathrm{MgO}$ & 1.82 & 1.27 & 1.51 & 0.87 & 1.03 & 0.67 & 1.39 & 0.63 & 0.53 \\
$\mathrm{Na}_{2} \mathrm{O}$ & 0.72 & 1.87 & 0.62 & 0.19 & 0.88 & 0.41 & 0.63 & 0.19 & 0.22 \\
$\mathrm{~K}_{2} \mathrm{O}$ & 3.37 & 3.18 & 2.42 & 1.92 & 1.54 & 1.05 & 2.98 & 0.36 & 0.35 \\
$\mathrm{TiO}_{2}$ & $<1$ & $<1$ & 0.74 & 0.39 & 0.66 & 0.33 & $<1$ & $<0.06$ & $<0.06$ \\
$\mathrm{SO}_{3}$ & 0.31 & 0.17 & 0.46 & 0.27 & 0.83 & 0.62 & 5.12 & 1.02 & 0.74 \\
$\mathrm{CaO}$ & 2.09 & 1.25 & 2.77 & 1.40 & 0.32 & 3.53 & 6.36 & 0.47 & 0.51 \\
$\mathrm{CaO}$ libre & 0.11 & 0.04 & 0.22 & 0.20 & 0.30 & 0.20 & 1.06 & --- & --- \\
\hline
\end{tabular}


The chemical composition of the inorganic components in the samples studied expressed as oxides is given in Table 3 . These analyses were carried out to find any possible influence of a given component on mercury capture. The composition differs considerably between raw fly ashes, the fly ashes concentrated with carbon particles and the activated carbons. No relation was found between the compositions of each sample and mercury capture. For instance, CTSR and CTA have a similar composition and yet the maximum retention capacity is higher in CTSR than in CTA in all conditions. CTP behaves as one of the worse sorbents for mercury in most conditions and yet CTP also has a similar composition to CTSR with the exception of the higher quantities of the limestone-derived components used in the power plant for capturing sulfur ( $\mathrm{CaO}, \mathrm{CaO}$ free and sulfur).

\subsection{Influence of mercury species in gas phase}

The influence of the mercury species in gas phase will be discussed on the assumption that the species of mercury during the experiments were $\mathrm{Hg}(\mathrm{g})$ and $\mathrm{HgCl}_{2}(\mathrm{~g})$. According to a theoretical assessment of thermodynamic equilibrium data at $120^{\circ} \mathrm{C}$ (temperature of the sorbent bed), if $\mathrm{Hg}^{0}$ were the source of the element in the combustion and inert atmospheres, $\mathrm{Hg}(\mathrm{g})$ would be the main species present in gas phase, whereas $\mathrm{HgCl}_{2}(\mathrm{~g})$ would be the main species, if $\mathrm{HgCl}_{2}$ were the solid evaporated. [11,14].

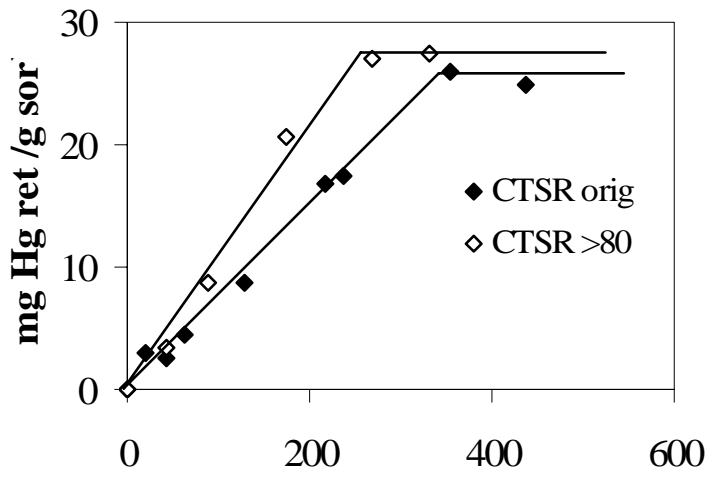

mg Hg evap/g sorb

(A)

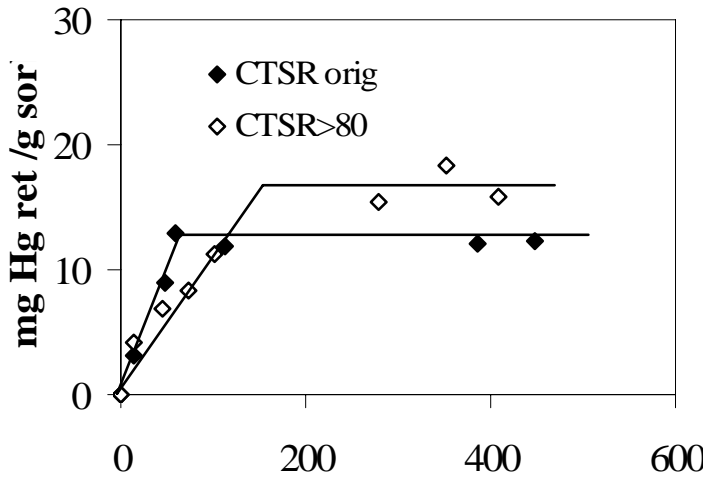

mg Hg evap/g sorb

(B)

Figure 1: An example of retention for $\mathrm{Hg}^{0}$ (a) and $\mathrm{HgCl}_{2}$ (b) in CTSR fly ash in the combustion atmosphere
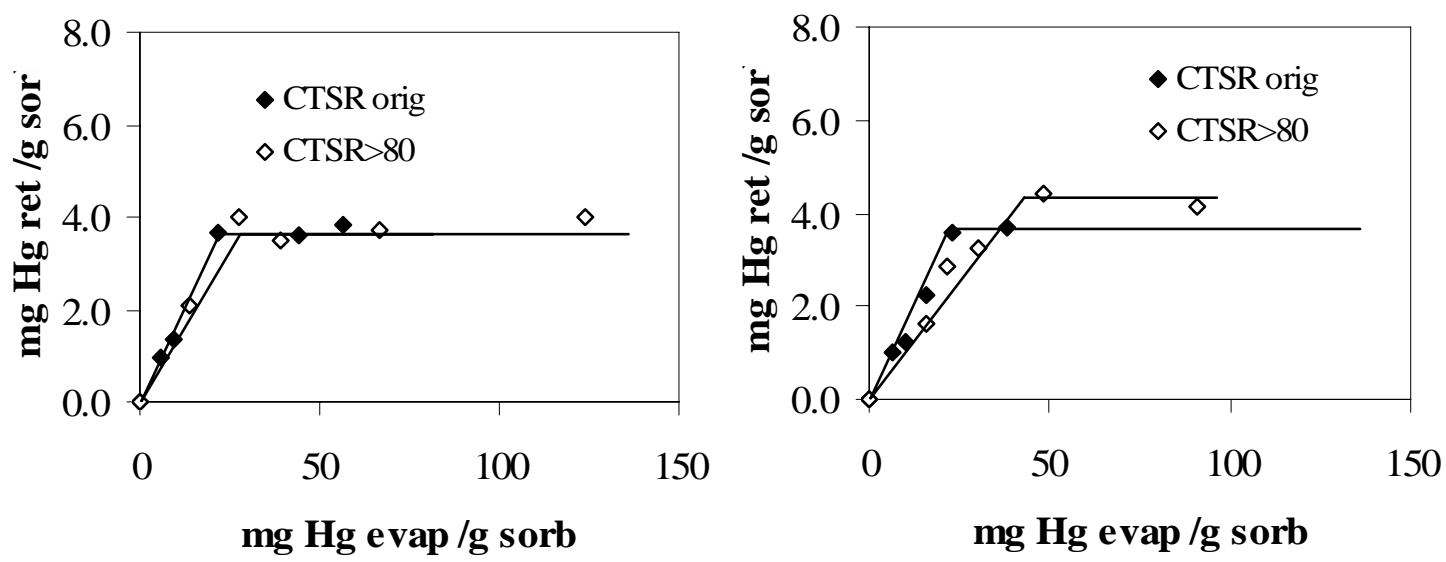

Figure 2: An example of retention of $\mathrm{Hg}^{0}$ (a) and $\mathrm{HgCl}_{2}$ (b) in CTSR fly ash in an inert atmosphere 
As an example, Figures 1-2 show the retention of the two mercury species in experiments for CTSR. The quantity of element retained was plotted against the quantity of element passed through the sorbent. The values of the retention capacities and efficiencies for all the materials checked can be compared in Table 1. The results obtained clearly demonstrate that fly ashes have a different retention capacity for both species. However, this capacity may be modified by the gas atmosphere. In an inert atmosphere MRC is higher for $\mathrm{HgCl}_{2}$ than for $\mathrm{Hg}^{\circ}$ except in CTSR when it is similar. CTSR fly ash, as well as its fraction enriched in unburned particles CTSR $>80$, are the best sorbents for both species and in all conditions. In the combustion atmosphere, retention capacities for $\mathrm{HgCl}_{2}$ are similar to or lower than those for $\mathrm{Hg}^{0}$ with the exception of those reached by the CTP fly ash. (Table 1). The capture of $\mathrm{Hg}^{\circ}$ in RB3 is the same in the two gas atmospheres but lower than in most fly ashes in the combustion atmosphere. The retention of $\mathrm{HgCl}_{2}$ in the commercial activated carbons which may involve physical adsorption is similar in RBHG3 and RB3 and higher than in most fly ashes, with the only exception of CTSR. This may be related to the common surface properties of these carbons.

\subsection{Influence of the gas atmosphere}

The influence of the gas atmosphere on retention has already been mentioned. Retention capacities for the species formed from $\mathrm{Hg}^{0}$ evaporation in the combustion atmosphere, attained values as high as $13 \mathrm{mg} \mathrm{g}^{-1}$ and $27 \mathrm{mg} \mathrm{g}^{-1}$ in the CTA and CTSR fly ashes compared to $0.30 \mathrm{mg} \mathrm{g}^{-1}$ and $3.8 \mathrm{mg} \mathrm{g}^{-1}$ in the inert atmosphere (Table 1, Figures 1-2). The different behavior observed in the activated carbons in which retention was similar for both atmospheres and lower than in the fly ashes has already been discussed and explained in a previous work [14], as being due to the possible effects of the inorganic components of the fly ashes on mercury oxidation. This would seem to suggest that the species retained in the fly ashes in the combustion atmosphere was not $\mathrm{Hg}^{\circ}$, but probably an oxidized mercury compound. A possible explanation for this could be that oxidized $\mathrm{Hg}$ is the species retained in the combustion atmospheres while $\mathrm{Hg}^{0}$ is the one retained in the inert atmosphere when $\mathrm{Hg}^{0}$ is the source of mercury in gas phase. $\mathrm{HgCl}_{2}(\mathrm{~g})$ is assumed to be the species retained in all atmospheres when $\mathrm{HgCl}_{2}$ is the source of mercury.

\section{CONCLUSIONS}

A comparison between the results obtained from the fly ash and activated carbon samples indicates that the retention of $\mathrm{Hg}^{0}$ is greatly influenced by the gas atmosphere. The capture of $\mathrm{Hg}^{0}$ in the fly ashes studied is higher in a typical combustion atmosphere than in an inert atmosphere unlike the case of activated carbons, where capture is similar for both atmospheres. The nature of the fly ashes is determinant in the control of mercury capture and the concentration and characteristics of the unburned particles also play a role. The fly ashes obtained from PCC plants are more efficient for mercury retention than those obtained from FBC.

\section{ACKNOWLEDGEMENTS}

The results of this work were obtained as part of the projects PPQ2001-2359-C02-02 and CTM2004-04252.CO2-02/TECNO 


\section{REFERENCES}

1. http://www.ecoba.org

2. Colin R.W. and French D. (2006) 'Determination of glass content and estimation of glass composition in fly ash using quantitative X-ray diffractometry', Fuel 85, 2268-2277.

3. U.S. Environmental Protection Agency, http://www.epa.gov/mercury

4. http://europa.eu.int/comm/environment/chemicals/mercury/index.htm

5. Sakulpitakphon T., Hower J.C., Trimble A.S., Schram W.H. and Thomas G.A. (2000) 'Mercury capture by fly ash: study of the combustion of a high-mercury coal at a utility boiler', Energ. Fuel., 14, 727-733.

6. Dunham G.E., DeWall R.A. and Senior C.L. (2003) 'Fixed-bed studies of the interactions between mercury and coal combustion fly ash', Fuel Process. Technol. 82, 197-213.

7. López-Antón M.A., Díaz-Somoano M., Spears D.A. and Martínez-Tarazona M.R. (2006) 'Arsenic and selenium capture by fly ashes at low temperature', Environ. Sci. Technol., 40, 39473951.

8. Díaz-Somoano M. and Martínez-Tarazona M.R. (2002) 'Retention of trace elements using fly ash in a coal gasification flue gas', J Chem. Technol. Biotechnol., 77, 396-402.

9. Clarke L.B. and Sloss L.L. (1992) 'Trace elements-emissions from coal combustion and gasification'. IEACR/49 IEA Coal Research, London, 111pp.

10. Mahuli S., Agnihotri R., Chauk S., Ghosh-Dastidar A. and Fan L.S. (1997) 'Mechanisms of arsenic sorption by hydrated lime', Environ. Sci. Technol., 31, 3226-3231.

11. López-Antón M.A., Díaz-Somoano M. and Martínez-Tarazona M.R. (2007) 'Mercury retention by fly ashes from coal combustion: Influence of the unburned coal content', Ind Eng Chem. Res., 46, 927-931.

12. Pavlish J.H., Sondreal E.A., Mann M.D., Olson E.S., Galbreath K.C., Laudal D.L. and Benson S.A. (2003) 'Status review of mercury control options for coal-fired power plants', Fuel Proc. Technol., 82(2-3), 89-165.

13. Li Z., Luo X. and Hwang J.Y. (2002) 'Unburned carbons from fly ash for mercury adsorption II: Adsorption Isotherms and Mechanisms', J Min Mat. Cgara, Eng., 1, 79-96.

14. López-Antón M.A., Díaz-Somoano M. and Martínez-Tarazona M.R. (2007) 'Retention of elemental mercury in fly ashes in different atmospheres', Energ. Fuel., 21, 99-103.

15. López-Antón, M.A. (2004) 'Retención de compuestos gaseosos de Hg, As y Se en sorbentes sólidos: aplicación a la combustión y gasificación de carbón'. Thesis, University of Oviedo, Spain. 